\title{
Usability study of a vineyard teleoperated compost spreader
}

\author{
Ester Ferrari and Eugenio Cavallo* \\ Institute for Agricultural and Earth Moving Machines (IMAMOTER), Italian National Research Council (CNR), \\ Strada delle Cacce, 73 - 10135 - Torino, Italy.
}

\begin{abstract}
Teleoperation has been widely applied in modern industry because of a variety of advantages, such as providing replaceable surrogates for humans in dangerous or difficult working environments over long distances. In this paper, a usability evaluation study of a teleoperation system for a compost spreader robotic machine is presented. The machine has been designed for the application of compost in small and stepping parcels of hilly vineyards. Driving and working tasks can be controlled remotely by a portable piloting unit, reducing the risk for the operator in the event of machine overturning. Participants of the study were asked to perform a series of tasks and sub-tasks and to vocalize their thoughts while working with the machine. The tasks were designed to simulate typical user experience. Once all the tasks were accomplished each participant was asked to fill a questionnaire. The evaluation considered aspects such as learnability, ease of use, understandability, controllability, frustration, mental effort, distraction, clarity of presentation, perceived usefulness, temporal efficiency and machine aesthetic. Results show that usability evaluation helped detecting design deficiencies in the teleoperated compost spreader machine.
\end{abstract}

Keywords: evaluation, users, agriculture, remote device, portable piloting unit.

\section{Introduction}

Mobile devices are embedded in daily routines and represent the most common and wide used technology today. Although the agricultural industry is increasingly technology-driven, mobile technology remains under-utilized [6].

Teleoperation has been widely applied in modern industry [5] because of a variety of advantages, such as providing replaceable surrogates for humans in dangerous or difficult working environments over long distances, potentially improving productivity, and reducing risks and costs [7].

Hilly vineyard is a typical case of hazardous environment for agricultural activity. The machine used for manure or compost spreading and pesticide application between rows of a hilly vineyard may be at risk of rolling over depending on a series of elements, such as the mass carried by the machine, the gradient of the slope and the terrain.
The heavier is the mass carried by the machine resulting from the sum of the mass of the vehicle plus the mass of the product carried (organic substance or solution of water and chemicals) - and the higher is the distance from the ground of the center of gravity of these masses, the greater is the risk of vehicle overturning, hence, the hazard for the operator.

A solution to reduce to zero the risk for the human could be to design and develop a teleoperation machine for compost spreading, avoiding the presence of the operator on the machine, or at its close distance.

When a new technology is introduced in a field of activity the demands placed on the workers' skills increase [20] and it successful diffusion depends largely on their merits being communicated between users and potential users [21]. Therefore, developing a machine design according to user-centred approach and conducting usability evaluation study is a step toward product success $[14,16,18]$.

\footnotetext{
*Corresponding author. E-mail: e.cavallo@imamoter.cnr.it.
} 


\section{Usability Evaluation Study}

In this paper, a usability evaluation study of a teleoperation system for a compost spreader robotic vehicle is presented.

The participants of the study were asked to perform a series of tasks and to explain what they were thinking about while working with the machine. The tasks were designed to simulate the typical user experience.

The teleoperated compost spreader has been designed to be used by farmers for the application of this material in small and stepping parcels of hilly vineyards.

\subsection{Definition of Usability}

The concept of usability has been in existence since the 1980s [8]. It has its roots in usability engineering, where HCI (human-computer interaction) examines how users interact with computer technology and looks at ways of making this interaction effective.

Probably its best known definition is by Nielsen [13]: usability is about learnability, efficiency, memorability, errors, and satisfaction.

ISO 9241-11 [10] and ISO 13407 [9] are two important standards related to usability: the former one provides the definition of usability and the latter one gives guidance for designing usability and can be regarded as an important supplement to the usercentered design literature.

Rather than describing different usability methods, ISO 13407 [9] describes usability at a level of principles, planning and activities. Moreover, it explicitly uses the standard definition of usability from ISO 9241-11 [10] as a reference for usability. ISO 9241-11 [10] defines usability as "the extent to which a product can be used by specified users to achieve specified goals with effectiveness, efficiency and satisfaction in a specified context of use".

Generally, this definition represents a 'broad' approach [2]: usability is about supporting users in achieving their goals in their work, it is not only a characteristic of a user interface. The definition means that usability is, first of all, a function of users of a product or a system (specified users). Further, for each single user, usability is a function of achieving goals in terms of a set of attributes, such as effectiveness, efficiency and satisfaction, in a specific environment of use [11].

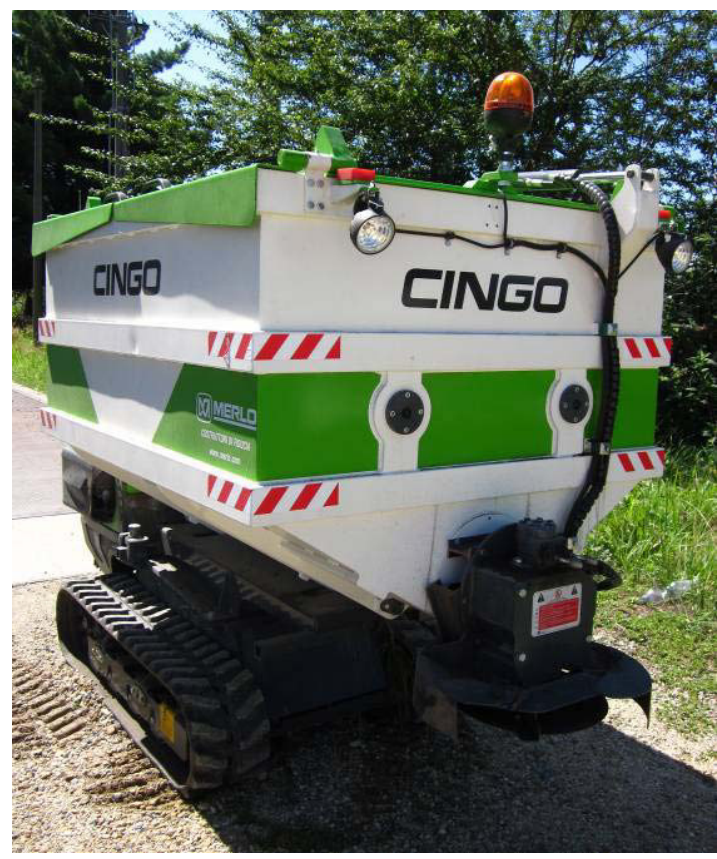

Fig. 1. Teleoperated compost spreader (view from the spreader side).

\subsection{Study Goals}

The goal of the usability study was to evaluate the system in terms of overall usability, functionality, and aesthetics through direct observations of the user experience.

Understanding how real users interact with the machine helps in making recommendations for product improvement. The primary purpose of the usability evaluation carried out in the present study is to improve machine design.

\subsection{Teleoperation system}

The teleoperated machine is a compost spreader (see Figure 1) for application of this material in small and stepping parcels, which are very common in some area of the Mediterranean Region. This machine has been designed on the experience on compost application in vineyards of Piedmont Region (Italy), where almost $90 \%$ of the vineyard surface is on hilly area [19].

The compost spreader is built on a multi-purpose chassis equipped with tracks, hydrostatic transmission and a $17 \mathrm{~kW}$ Diesel engine, that assures power for propulsion and actuation of the different implements that can be hosted on the vehicle. The dimen- 
sion of the machine is approximately $2 \mathrm{~m}$ long, $1.7 \mathrm{~m}$ wide and 1.8 high.

A quick-coupling system on the multi-purpose chassis makes possible to fit a large list of interchangeable tools: soil cultivation implements, turf-care machines, sprayer, transport appliances, and many others.

The compost distribution tool is made of a hopper for the compost storage, an internal auger for the mixing, and a rotating application device. The hopper has approximately $400 \mathrm{~kg}$ capacity and can change transversal inclination acting on a hydraulic actuator in order to increase transversal stability.

The commercial version of the machine is pedestrian-controlled, while the prototype used in the usability study is equipped with a portable piloting unit.

The portable piloting unit makes possible to control the vehicle from $100 \mathrm{~m}$ distance and its main advantage is to reduce the risks for the operator resulting, for example, from roll-over of the vehicle arising when it is used in stepping parcels, or from the contact and/or inhalation of dangerous substances managed with tools such as sprayers of chemical fertilizer spreaders.

\section{Methodology}

In order to identify the advantages and disadvantages of the machine, usability assessment was conducted. Participants took part in the assessment individually and had to perform a series of tasks representing typical situations in vineyards work.

Prior to starting the experiment, a short oral presentation about the usability study was given to all participants. The scenario of the usability test was presented and the tasks and sub-tasks were listed. Participants were asked to vocalize their thoughts while performing the sub-tasks. Once all the subtasks were accomplished each participant was asked to fill a questionnaire. In the meantime a researcher observed the interaction with the machine and filled an observation grid.

\subsection{Participants}

Representative users of the target population were involved in the study to perform given tasks. The target population of the product consists of people working in the agricultural field and who had showed some interest in the use of the teleoperated machine.
Almost everyone in the usability field agrees that there are diminishing returns from having more users do the same tasks: the more users you watch, the fewer new problems you see. According to Nielsen's studies $[15,16]$ the first three users are likely to encounter all of the most significant problems related to the tasks tested. Analyzing Nielsen's study Kingman and colleagues [12], based on the proportion of usability problems found by using various numbers of evaluators, built an equation to determine the optimal number of users for determining usability problems. They concluded that three to five experts would be the optimal for determining usability problems.

In this usability study six participants, representative of the target user population, have been involved.

\subsection{Task scenarios}

Researchers asked participants to complete a series of tasks during each testing session. These tasks were formulated based on two major functions of the machine: managing the hopper and spreading the compost between vineyard rows.

As showed in Table 1 five tasks were defined. Each task was further broken up into sub-tasks with clear criteria for success. The research team chose to word the tasks and sub-tasks as explicitly as possible to minimize questions by the participants.

The tasks were performed on the same path, ensuring consistent conditions for all participants.

\subsection{Thinking aloud}

The thinking aloud is a technique commonly used in usability testing. During the course of the test the participant is asked to vocalize their thoughts, feelings, and opinions while interacting with the machine to complete the tasks. The purpose of this technique is to make explicit what is implicit.

Thinking aloud allows an understanding of how the user approaches the interface and what considerations they have in mind when using it. If the participant expresses that the sequence of steps dictated by the machine to accomplish the tasks is different from what they expected, the usability of the machine interface must be questioned.

\subsection{Observation Grid}

The observation grid is a tool to gather data during the usability test. The grid was developed to collect information on how users achieved or failed each 
sub-task, the time needed to accomplish it and the errors or deviations which were made. The information was collected by a single observer, in order to avoid dealing with the inter-observer variability bias.

It has been decided to carry on a direct observations even if, compared to a delayed observations based on video recordings, it results in less precise measurements of task duration. Nevertheless, it has the evident advantage of being significantly less time consuming.

\subsection{Questionnaire}

In addition to asking participants to talk aloud during the accomplishment of the usability tasks, the research team collected information from participants by means of a questionnaire with a 5-points Likert scale, and few open-ended questions.

The questionnaire was used to measure participants' perceptions of the usability and usefulness of the machine. Once the participants had completed all the tasks, their feedbacks on the machine across several criteria were collected.

The questionnaire used is an adaptation of the Post Study Satisfaction User Questionnaire (PSSUQ) [13]. The following dimensions were used to measure the usability of the teleoperated compost spreader: learnability, ease of use, understandability, controllability, frustration, mental effort, distraction, clarity of presentation, perceived usefulness, temporal efficiency and machine aesthetic.

Table 1

List of tasks and sub-tasks.

\begin{tabular}{|c|c|c|}
\hline \multicolumn{2}{|l|}{ Task 1: Starting up the machine } & \multirow{2}{*}{$\begin{array}{l}\text { Errors or } \\
\text { deviations }\end{array}$} \\
\hline Sub-tasks & Description of Expected Actions & \\
\hline 1.1 Turning on the machine ignition & Start the machine by turning the ignition key to the right (on ST). & \\
\hline 1.2 Regulate the accelerator & $\begin{array}{l}\text { Move up the accelerator lever to increase the power of the engine and move it } \\
\text { down to decrease it. }\end{array}$ & $\mathrm{X}$ \\
\hline 1.3 Wearing the portable piloting unit & $\begin{array}{l}\text { Remove the piloting unit from its initial position on the machine and wear the } \\
\text { remote control by using the neck-cord. }\end{array}$ & $\mathrm{X}$ \\
\hline 1.4 Activating the portable piloting unit & Turn right the key located on the left side of the portable piloting unit. & $\mathrm{X}$ \\
\hline \multicolumn{2}{|l|}{ Task 2: Managing the hopper } & \multirow{2}{*}{$\begin{array}{l}\text { Errors or } \\
\text { deviations }\end{array}$} \\
\hline Sub-tasks & Description of Expected Actions & \\
\hline 2.1 Open hopper doors & Move up the middle lever on the machine control. & $\mathrm{X}$ \\
\hline 2.2 Tilt the hopper & Move up and down the first lever on the portable piloting unit. & $\mathrm{X}$ \\
\hline 2.3 Turn on the mixer & Move up the middle lever on the machine control. & \\
\hline 2.4 Close hopper doors & Move down the middle lever on the machine control. & \\
\hline \multicolumn{2}{|c|}{ Task 3: Moving from the loading position to the vineyard } & \multirow{2}{*}{$\begin{array}{r}\text { Errors or } \\
\text { deviations }\end{array}$} \\
\hline Sub-tasks & Description of Expected Actions & \\
\hline 3.1 Set the speed & Turn the selector switch on the top right side from high speed (1) to slow (0). & $\mathrm{X}$ \\
\hline 3.2 Move the machine in a straight line & $\begin{array}{l}\text { Move down simultaneously the two levers on the portable piloting unit controlling } \\
\text { the right and left caterpillar tracks. }\end{array}$ & $\mathrm{X}$ \\
\hline \multicolumn{2}{|c|}{ Task 4: Spreading operations of the vineyard } & \multirow{2}{*}{$\begin{array}{l}\text { Errors or } \\
\text { deviations }\end{array}$} \\
\hline Sub-tasks & Description of Expected Actions & \\
\hline 4.1 Starting the spreading system & Move up the second lever on the portable piloting unit and turn the holds switch. & \\
\hline 4.2 Spreading between the rows & $\begin{array}{l}\text { Move down simultaneously the two levers on the portable piloting unit controlling } \\
\text { the right and left caterpillar tracks, until reached the end of the vineyard row. }\end{array}$ & $\mathrm{X}$ \\
\hline 4.3 Stopping the spreading system & Move down the second lever on the portable piloting unit. & \\
\hline 4.4 Turning the machine of $180^{\circ}$ & $\begin{array}{l}\text { Move the two levers on the portable piloting unit controlling the caterpillar tracks } \\
\text { (one up and the other down) in order to make the machine rotate of } 180^{\circ} \text { and to be } \\
\text { ready to spread compost between the next two vineyards rows. }\end{array}$ & $\mathrm{X}$ \\
\hline $\begin{array}{l}\text { 4.5 Repeating the sub-task 3.1-3.4 with } \\
\text { fast speed until there is no compost left }\end{array}$ & $\begin{array}{l}\text { Turn the selector switch on the top right side from slow speed }(0) \text { to high speed (1), } \\
\text { move up the second lever on the portable piloting unit and turn the holds witch, etc. }\end{array}$ & \\
\hline \multicolumn{2}{|l|}{ Task 5: Return to the loading position } & \multirow{2}{*}{$\begin{array}{l}\text { Errors or } \\
\text { deviations }\end{array}$} \\
\hline Sub-tasks & Description of Expected Actions & \\
\hline 5.1 Return to the loading position & $\begin{array}{l}\text { Move the two levers on the portable piloting unit controlling the caterpillar tracks } \\
\text { in order to make the machine reaching the loading point/starting position. }\end{array}$ & $\mathrm{X}$ \\
\hline 4.2 Stop the machine & $\begin{array}{l}\text { Turn the ignition key to the left (on OFF) and replace the portable piloting unit on } \\
\text { the machine. }\end{array}$ & \\
\hline
\end{tabular}




\subsection{Pilot Test}

Before the formal usability tests, a pilot test was conducted. Its main purpose was to familiarize the team with the real testing environment and procedures, while identify possible problems with the equipments, documents, location or testing procedure.

The subject for the pilot test was a team member who had not been involved in composing the tasks list and the questionnaire. The subject was assumed to simulate a real test participant as much as possible.

Based on the observations, as well as the feedback from the subject, some problems with the tasks and sub-tasks that could cause confusion have been identified. To avoid such problems during formal tests, the team modified the wording of the introduction script, tasks, and post-task questionnaire. The final tasks list is the one showed in Table 1.

\subsection{Data analysis}

The data analysis techniques used to analyze questionnaire quantitative data included elementary descriptive statistics. The qualitative data collected from responses to the open-ended questions of the questionnaire and from the observation grid were coded and structured into categories [3]. This process served to organize the qualitative data into a meaningful context.

\section{Results}

The information obtained from the analysis of the questionnaire and the observation grid allowed discovering the areas most in need of improvement and redesign. From the initial descriptive statistics, it was clear that participants interacting with the machine had a personal experience, expressing slightly different opinions one from another. For example, half of the sample have found task 1 difficult or very difficult to complete, while the other half have found it easy or very easy. Often participants' responses spread out throughout the questionnaire scale. These considerations suggest that the involvement of six users yielded to not redundant data and made it possible to obtain good information toward user's experience improvement.

Learnability is the first attribute that new users of a machine become aware of since they will be endeavoring to learn how to use it [4]. How easy it is to learn to use the machine will affect their attitudes towards it. The questionnaire helped distinguishing between the ease of learning and the ease of use. Learnability resulted higher compared to the ease of use. Half of the participants reported that the machine was easy to use, and two third found it easy to learn.

On the aspect of machine understandability, participants' opinions were spread throughout the questionnaire scale. Despite of that most of them didn't experience frustration in the use of the machine.

Handling the machine was found neither difficult nor easy. Participants' opinions on machine controllability were spread out throughout the questionnaire scale as well, with most opinions being negative. Clarity of information presentation obtained the same result. Nevertheless, according to the participants, tasks execution didn't require much mental effort. One third of the participants felt they were distracted while using the machine, as it didn't require much attention to be controlled.

The answers related to the overall temporal efficiency of the machine are spread throughout the questionnaire scale. The open questions and the observation grid helped understanding that for some tasks machine temporal efficiency is adequate (i.e. task 2), while for others it was unsatisfactory and the machine response was found not fast enough, such as the case of the sub-task 3.2.

The machine aesthetic was judged neither beautiful nor ugly. Most of participants were satisfied, deemed the machine pleasant to use and perceived it to be useful for compost spreading, particularly in hilly vineyards.

On a general note it can be said that from the questionnaire the machine system interface was not completely "transparent" and it didn't always provide the operator with clear cues as to what needs to be done. In particular the data analysis of the open ended questions and the observation grid gave evidence for evaluating the machine system interface as nor clear neither well organized. On the same line, the questionnaire results related to the understandability aspect show that the controls - on the portable piloting unit, as well as on the compost spreader vehicle were not easy to understand and that there is room to improve the usability of the system, and alongside with it, the user experience.

In order to investigate the aspects in need of improvement in more detail, the combined analysis of qualitative and quantitative data advised the need to separate the issues related to the redesign of the compost spreader vehicle from those related to the portable piloting unit. 


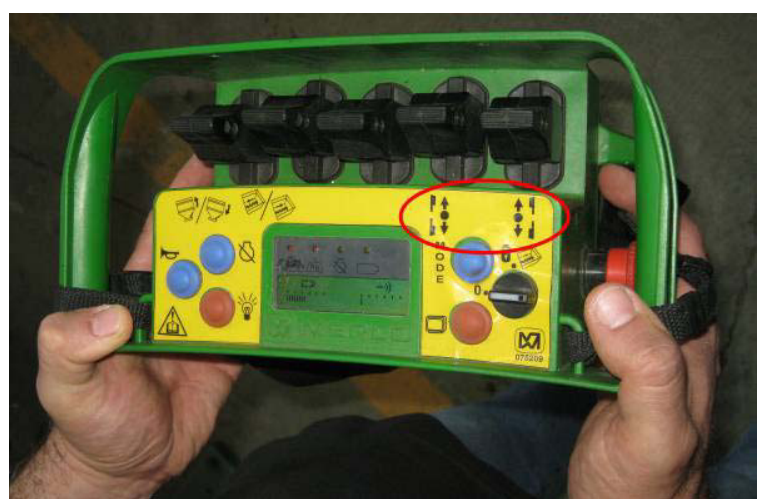

Fig. 2. Portable piloting unit of the compost spreader machine; the circle indicates the icons related to the lever controlling caterpillar tracks movements.

\subsection{Portable piloting unit}

Weight and dimensions of the portable piloting unit were judged appropriate. On the contrary, the symbols and icons used in the portable piloting unit were found fairly confusing and unclear (see Figure 2 ). Icons are common interface component that employ images to represent an action that can be carried out by the operator [1]. One disadvantage is that they can be misinterpreted or misunderstood. This is especially the case of the images related to the lever controlling caterpillar tracks movements (see Figure 2).

The location of the key to activate the portable piloting unit was perceived as unfriendly (see Figure 3 ). Indeed, it is placed on the left side of the piloting unit, in a hidden position from the operator's view when the unit is held as shown in Figure 2. Some participants mistook it for the control switch to hold the auger in motion (Figure 2, black switch with 0 and 1) However, the analysis of the observation grid data suggested that its position doesn't need to be modified. During the spreading operations the user needs to turn this key only once and the fact that it is not positioned on the same surface as the other controls gave the advantage to reduce the quantity of information presented in this small area. The use of a color for the key which is different from the background color would make it easier to find.

Different colors should be used also for the black levers (see Figure 2) in order to convey meaning to the user. Simplicity and consistency must be respected in the choice of the colors. Color contributes to a user interface that is pleasing in appearance and more importantly easier to use.

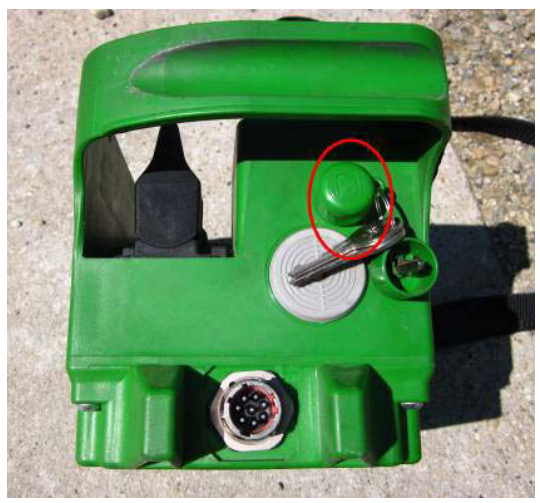

Fig. 3. Portable piloting unit of the compost spreader machine (view from the right side); the circle indicates the key to activate the piloting unit.

From the data analysis it resulted that the system violets one of Nielsen's heuristics [14] such as the visibility of system status by not keeping the user informed with appropriate feedback. Indeed the machine doesn't provide the user with any feedback about its status during the compost spreading phase. An auditory or visual feedback on the portable piloting unit would be very important especially in those situations when the machine is far away from the position of the operator and therefore they can't see if there is any compost left in the hopper that can still be distributed or if there are any problems with the spreading of the material (e.g. the high level of humidity of the compost can result in blocks of compost material which can get stuck avoiding it spreading).

The results of the field trials have also indicated that equipping the piloting unit with a warning signal (auditory or haptic feedback) in supporting collision avoidance with vines or support posts of the grape trellis, would improve task performance, as well as the usability of the machine.

An additional aspect that needs to be reconsidered by engineers and designers is the impossibility to control the machine engine power through the use of the portable piloting unit, meaning that the operator can increase or decrease the speed only when they are next to the machine itself. Adding the possibility to regulate the speed by the use of the portable piloting unit would increase machine usability.

The last aspect that should be reconsidered is the position of the portable piloting unit. One participant found very difficult to extract and to reposition it. A different solution would increase efficiency. 


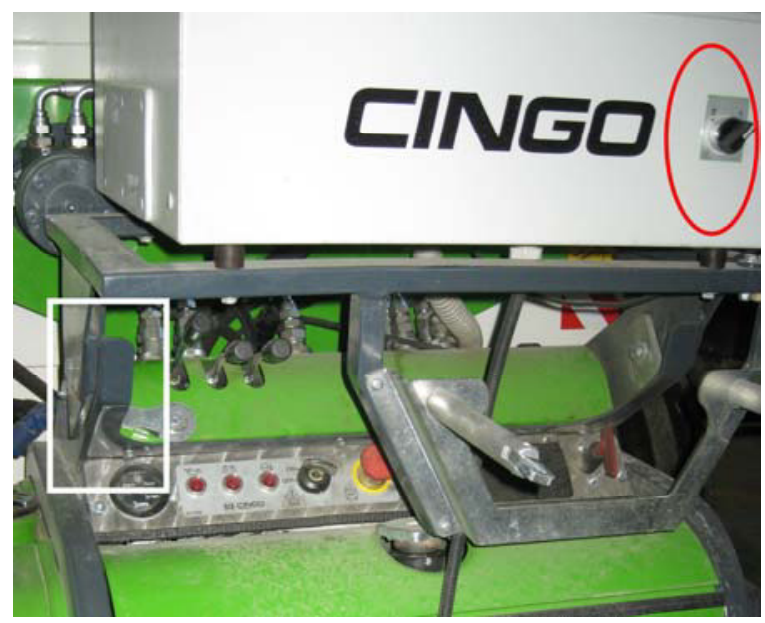

Fig. 4. Detail of teleoperated the compost spreader (view from control side); the circle indicates speed switch, the square indicates the accelerator lever.

\subsection{Compost spreader vehicle}

From the observation grid it was clear that usability test participants showed similar responses in executing the sub-task 3.1 "set the speed". To complete this task all participants needed assistance to find the correct switch. Indeed, the selector switch which regulates the machine speed is positioned on the compost spreader vehicle, but it is not grouped with the other elements on the control dash (Figure 4). In addition to its isolated location, the absence of the usual operating symbols indicating speeds (i.e. rabbit and turtle), replaced by the number 0 standing for slow and 1 for high speed, made participants mistaken it for the starting switch.

Similarly the majority of the participants demonstrated similar issues in completing the sub-task 1.2 "regulate the accelerator". Four of the six users could not perform it without assistance. The accelerator lever, a small black lever positioned on the dash control of the machine, resulted difficult for them to find. Indeed, its location next to the levers controlling the hopper is hardly noticeable (Figure 4).

Usability assessment showed that it was difficult for the participants to control the movement of the vehicle along the slope and especially during a $180^{\circ}$ turn, due to the operation time lag. To improve its usability the machine requires being equipped with a more powerful engine.

On a general note, the observations allowed to notice that the machine was nearly always operated by the usability test participants at its maximum engine power, suggesting that some of the difficulties faced by the participants (i.e. controlling the movement of the machine along the slope) were the consequence of the lack of adequate machine power. Hence, equipping the vehicle with a more powerful engine will result in better system performances and more usable machine.

\section{Conclusion}

Usability creates value as well as affects technology adoption. The study was conducted to determine users' perception on the usability aspects of the machine prototype. It identified usability problems, as well as provided specific design recommendations in terms of specific features or interface elements of the machine.

Suggestions on how to improve the prototype in order to allow more accurate task completion and increase its usability have been collected and suggested to the designers. For example, the field trials showed that it could be useful to endowed the portable piloting unit with an accelerator lever to switch the speed of the engine between low and high, in order to allow the operator to modify machine speed when its position is far away from it (i.e. when the machine is returning to the re-filing position after spreading all the compost in the hopper).

Participants contributed with new ideas on how existing features could be improved and new features developed. Between others the following improvements have been suggested:

- auditory and/or visual feedback on the portable piloting unit to give feedback on the actual compost spreading action (with the possibility of turning it off);

- $\quad$ auditory or haptic feedback on the portable piloting unit to help the operator to avoid collision with vines or support posts of the grape trellis;

- engine power increase, in order to allow a more reliable execution of the tasks in term of time response and precision spreading of quantity material.

In conclusion, the assessment conducted made it clear that the prototype needed to be modified and that the usability test allowed to detect the issues in need of improvement. Increased machine usability, according to the usability tests results, will play an important role for good market performances. 


\section{References}

[1] I. Benbasat, and P. Todd, An Experimental Investigation of Interface Design Alternatives: Icon vs. Text and Direct Manipulation vs. Menus, International Journal of Man-Machine Studies, 38, 3, (1993), 369-402.

[2] N. Bevan, Quality in use: incorporating human factors into the software engineering lifecycle. In ISESS (1997), 533-552.

[3] M. Ely, Anzul, M., Friedman, T., Garner, D. and A. Maccormack Steinmetz, Doing Qualitative Research: Circles Within Circles. Falmer Press, 1995

[4] X. Faulkner,, Usability Engineering. London, MacMillan Press Ltd., 2000.

[5] T. Fong, and C. Thorpe, Vehicle teleoperation interfaces, Autonomous Robots, 11, 1 (2001), 9-18.

[6] A. Grantham and G. Tsekouras, Diffusing wireless applications in a mobile world, Technology in Society, 27 (2005), 85-104.

[7] J. Gulliksen, T. Gross, and P. Kotzé, Human computer interaction: INTERACT 2009, Proceedings of the 12th IFIP International Federation for Information Processing Conference, Ed. Springer (2009), 93-96

[8] A. Head, Web redemption and the promise of usability", Online, 23, 6 (1999), 20-3.

[9] ISO/IEC. 13407 Human-Centred Design Processes for Interactive Systems, ISO/IEC 13407: 1999.

[10]ISO/IEC. 9241-14 Ergonomic requirements for office work with visual display terminals (VDT)s - Part 14 Menu dialogues, ISO/IEC 9241-14: 1998.

[11]T. Jokela, N. Iivari, J. Matero, and M. Karukka, The Standard of User-Centered Design and the Standard Definition of Usability: Analyzing ISO 13407 against ISO 9241-11. In Proceedings of CLIHC ,Rio de Janeiro, Brazil, (2003) 53-60.
[12]D. M. Kingman, A. M. Yoder, N. S. Hodge, R. Ortega, and W. E. Field, Utilizing Expert Panels in Agricultural Safety and Health Research, Journal of Agricultural Safety and Health 11 (2005), 61-74.

[13]J.R. Lewis, IBM computer usability satisfaction questionnaires: psychometric evaluation and instructions for use. International Journal of Human Computer Interaction, 7 (1995), 57-78.

[14]J. Nielsen, Heuristic evaluation. In: Nielsen, J., Mack, R.L. (Eds.), Usability Inspection Methods. John Wiley and Sons, New York, NY, 1994

[15]J. Nielsen, Scenarios in discount usability engineering. In: Caroll, J.M. (Ed.), Scenario-based Design: Envisioning Work and Technology in System Development. John Wiley and Sons, New York, NY, 1995.

[16]J. Nielsen, Designing Web Usability, New Riders Publishing, Indianapolis, IN (2000).

[17]J. Nielsen, Why you only need to test with 5 users. Alertbox. Retrieved May 1, 2002, from www.useit.com/alertbox /2000319.html (2000).

[18]D.A. Norman , The Psychology of Everyday Things. Basic Books, New York, 1988.

[19]Piedmont Regional Administration, Viticultura e Enologia. Date of access: May 2011, Available from www.regione.piemonte.it/agri/viticoltura/documentazione/ban chedati.htm (2011).

[20]R.E. Plant, Site-specific management: the application of information technology to crop production, Computers and Electronics in Agriculture, 30 (2001), 9-29.

[21]E.M. Rogers, Diffusion of innovations. New York: The Free Press, 1995. 